\title{
Sirtuin 1 promotes the proliferation of C2C12 myoblast cells via the myostatin signaling pathway
}

\author{
LIANG WANG, TING ZHANG, YONGYONG XI, CUILI YANG, CHENGCAO SUN and DEJIA LI \\ Department of Occupational and Environmental Health, School of Public Health, \\ Wuhan University, Wuhan, Hubei 430071, P.R. China
}

Received July 9, 2015; Accepted May 16, 2016

DOI: $10.3892 / \mathrm{mmr} .2016 .5346$

\begin{abstract}
Accumulating evidence suggests that Sirtuin (Sirt)1 serves a significant role in proliferation and differentiation of myoblast cells; however the signaling mechanisms involved remain to be established. Myostatin (MSTN), a member of transforming growth factor- $\beta$ family, is an vital regulator of myoblast, fibroblast growth and differentiation. To determine if MSTN is involved in the regulation of myoblast cell proliferation by Sirt1, the present study administrated the Sirtl activator resveratrol, inhibitor nicotinamide (NAM) and MSTN inhibitor SB431542 to C2C12 myoblast cells. It was demonstrated that the Sirt1 activator, resveratrol, repressed, whereas the Sirt1 inhibitor, NAM, enhanced C2C12 myoblast cells proliferation in a Sirt1-dependent manner. SB431542 promoted the proliferation of $\mathrm{C} 2 \mathrm{C} 12$ myoblast cells and reversed the inhibition effect of NAM on $\mathrm{C} 2 \mathrm{C} 12$ myoblast cell proliferation. Additionally, resveratrol upregulated the mRNA expression of MyoD, but inhibited the expression of MSTN. Additionally, NAM significantly repressed the expression of MyoD and the phosphorylation of P107 (p-P107), but enhanced the expression of MSTN and the protein expression of P107. SB431542 significantly mitigated the effect of NAM on the expression of MyoD, P107 and p-P107. Taken together, these results indicated that Sirt1 promotes the proliferation of $\mathrm{C} 2 \mathrm{C} 12$ myoblast cells via the MSTN signaling pathway.
\end{abstract}

\section{Introduction}

Sirtuin (Sirt)1, a mammalian homologue of silent mating type information regulation 2 (1), is an $\mathrm{NAD}^{+}$-dependent histone/protein deacetylase, which regulates caloric restriction-mediated longevity in model organisms (2). It is also an important regulatory factor of cell defense (3) and is involved in

Correspondence to: Professor Dejia Li, Department of Occupational and Environmental Health, School of Public Health, Wuhan University, 115 Donghu Road, Wuhan, Hubei 430071, P.R. China

E-mail: dejialiwhu@sina.com

Key words: Sirtuin 1, myostatin, C2C12 myoblast cells, proliferation a wide variety of cellular processes, including differentiation, inflammation, energy metabolism, DNA repair and cancer (4). Resveratrol, which is a naturally occurring polyphenol found in grapes and red wine (5), has been found to activate Sirt1. Jackson et al (6) and Sauve et al (7) noted that NAM can inhibit Sirtl activity effectively both in vivo and in vitro.

Previously a series of researches have demonstrated that Sirt1 may promote cell proliferation $(8,9)$. Treatment with resveratrol can increase muscle mass of mdx mice, which is often used as a disease model for human muscular dystrophy (10). Consistent with this, overexpression of Sirt1 can promote muscle precursor cell proliferation and cell cycle progression (11). Additionally, associated with the Sirt1-mediated proliferation of $\mathrm{C} 2 \mathrm{C} 12$ cells were the bidirectional decreases and increases in the expression levels of the cyclin-dependent kinase inhibitors p21 ${ }^{\text {Waf1/Cip1 }}$ and p2 $7^{\text {Kip1 }}$, respectively. However, the underlying mechanism of Sirt1 in regulating the expression of $\mathrm{p} 21^{\mathrm{Waf} 1 / \mathrm{Cip} 1}$ and $\mathrm{p} 27^{\mathrm{Kip} 1}$ remains to be determined. Another mechanism for Sirt1-mediated cell proliferation is that Sirt1 may prolong cell survival date and inhibit the rate of cell death. For example, Sirt1 can induce the expression of superoxide dismutase 2 (Sod2/Mn-Sod), which may decrease the levels of reactive oxygen species and reduce oxidative stress-induced cell death in C2C12 myoblast cells (12). Additionally, Sirt1 can notably affect the expression of transcription factors, including FOXO, E2F1 and p53 $(13,14)$, which are important factors that regulate cell differentiation and apoptosis. As well as normal cells, Sirt1 can also promote the proliferation of tumor cells through inhibiting the differentiation of tumor cells (15). Although Sirt1 can improve myoblast proliferation, the specific mechanism(s) remain unknown.

Myostatin, a member of the transforming growth factor (TGF)- $\beta$ superfamily, has been shown to negatively regulate skeletal muscle myogenesis (16). Myostatin predominantly affects myoblast cells in the G1 phase and subsequently interferes with the progression into $\mathrm{S}$ phase to slow down myoblast proliferation (17). However, whether myostatin is involved in the Sirt1-mediated regulation of $\mathrm{C} 2 \mathrm{C} 12$ myoblast cell proliferation remains to be reported. Previous research found that the expression level of Sirt1 increased in myostatin-deficient mice (18). Futhermore, myostatin may inhibit myoblast proliferation by upregulating the expression of $\mathrm{p} 21^{\text {Waf } 1 / \text { Cipl }}$. The evidence suggested that certain correlation exists between 
Sirtl and myostatin in the regulation of cell proliferation (17). The present study co-incubated C2C12 cells with Srit1 activator, Sirtl inhibitor and myostatin inhibitor, and then assessed the cell growth and the expression of the myostatin pathway. These results indicated that myostatin is notably involved in Sirt1-mediated regulation of $\mathrm{C} 2 \mathrm{C} 12$ myoblast cell proliferation. These results may assist with the design of novel methods or targets for the therapy of muscular dystrophy.

\section{Materials and methods}

Cell culture. C2C12 myoblast cells were obtained from the Lab of College of Animal Science and Technology of Huazhong Agricultural University. The cells were cultured in Dulbecco's modified Eagle's medium (DMEM; Hyclone; GE Healthcare Life Sciences,. Logan, UT, USA) supplemented with $1 \%$ antibiotics (Gino Biomedical Technology Co., Ltd., Hangzhou, China) and $10 \%$ fetal bovine serum (Hyclone; GE Healthcare Life Sciences) in a humidified air of $5 \% \mathrm{CO}_{2}$ at $37^{\circ} \mathrm{C}$.

Reagents and antibodies. Resveratrol was purchased from Sigma-Aldrich (St. Louis, MO, USA). Immediately prior to use, a $0.1 \mathrm{M}$ stock solution stored at $-20^{\circ} \mathrm{C}$ was diluted to the desired concentration with culture medium, and the final concentration of DMSO for all treatments was maintained at $0.2 \%$. SB 431542 was purchased from Selleck Chemicals (Houston, TX, USA). NAM was from Beyotime Institute of Biotechnology (Hangzhou, China) and the Cell Counting kit (CCK)-8 was from Dojindo Laboratories (Kumamoto, Japan). The antibodies used were anti-myostatin rabbit polyclonal (Abcam, Cambridge, MA, USA; cat. no. ab98337), anti-P107 rabbit polyclonal (Abcam; cat. no. ab2451), anti-p-P107 rabbit polyclonal (Bioss, Inc., Woburn, MA, USA; cat. no. bs-5696R), anti- $\beta$-actin mouse monoclonal (Anbo, Changzhou, China; cat. no. E0012) and anti-rabbit secondary antibody (Abcam; cat. no. ab6721). Other reagents were from Goodbio Technology Co., Ltd. (Wuhan, China) or HyClone.

Cell proliferation assay. Exponentially growing $\mathrm{C} 2 \mathrm{C} 12$ myoblast cells $\left(8 \times 10^{3}\right.$ cells/well; $\left.100 \mu \mathrm{l}\right)$ were seeded into 96 -well plates $20-24 \mathrm{~h}$ prior to replacing fresh serum free medium containing the indicated concentrations of drug. SB431542 was added first, followed by NAM after $30 \mathrm{~min}$ in the group of the SB431542 combined with NAM. After incubation for $24 \mathrm{~h}$, culture medium was replaced with drug-free medium $(100 \mu \mathrm{l})$, and the effect of drug was examined by a CCK-8 assay, according to the manufacturer's protocol. Briefly, $10 \mu \mathrm{l}$ of CCK-8 was added to each well and the cells were further incubated away from light at $37^{\circ} \mathrm{C}$ for $1-3 \mathrm{~h}$. Absorbance was measured with excitation at $450 \mathrm{~nm}$ using a microplate reader (Bio-Rad Laboratories, Inc., Hercules, CA, USA).

5-Bromo-2-deoxyuridine (BrdU) assay. The cells were cultured in growth media for $12 \mathrm{~h}$, followed by BrdU treatment (BrdU $10 \mathrm{mg} / \mathrm{ml}$ stock solution in saline was diluted 1:1,000 in the culture medium) for $1 \mathrm{~h}$ prior to harvesting. After washing with phosphate-buffered saline (PBS), cells were then fixed for 20 min in $4 \%$ paraformaldehyde and permeabilized with $0.3 \%$ Triton X-100 for $10 \mathrm{~min}$. Following blocking with $10 \%$ goat serum in PBS for $1 \mathrm{~h}$, the cells were incubated with anti-BrdU antibody (1:200; BD Biosciences, San Jose, CA, USA; cat. no. 552598 ) at $4^{\circ} \mathrm{C}$ for $18 \mathrm{~h}$, followed by incubation with and the secondary goat anti-mouse immunoglobulin G antibody conjugated with Alexa Fluor 594 (1:1,000 dilution; Abcam; cat. no. ab150116) for $2 \mathrm{~h}$ at room temperature in the dark. The nuclei were visualized by 4',6-diamidino-2-phenylindole and images were captured using an Olympus microscope (IX71; Olympus, Tokyo, Japan).

Reverse transcription-quantitative polymerase chain reaction $(R T-q P C R)$. After treatment for $6 \mathrm{~h}$, the total RNA from C2C12 myoblast cells was extracted using TRIzol reagent (Invitrogen; Thermo Fisher Scientific, Inc., Waltham, MA, USA), according to the manufacturer's protocol. First-strand cDNA was synthesized using a PrimeScript ${ }^{\mathrm{TM}}$ RT reagent kit (Takara Bio, Inc., Dalian, China; cat. no. RR037A). DNA amplification was performed in a StepOne system (Applied BioSystems; Thermo Fisher Scientific, Inc.) using SYBR Green PCR kit (Takara Bio, Inc.; cat. no. RR420A) for Sirt1, MyoD and $\beta$-actin. The primer sequences are listed in Table I.

Western blotting. Following treatment for $24 \mathrm{~h}$, the C2C12 myoblast cells were harvested in phosphate-buffered saline, centrifuged at 5,000 g for $10 \mathrm{~min}$ at $4^{\circ} \mathrm{C}$ and the supernatant was then removed. The samples were homogenized in ice-cold radioimmunoprecipitation lysis buffer (Beyotime Institute of Biotechnology) with $1 \%$ protease inhibitor cocktail (Sangon Biotech, Shanghai, China) and 1\% phosphatase inhibitors (Goodbio Technology Co., Ltd.), and were incubated on ice for 20-30 min. The samples were centrifuged at 10,000 g for $10 \mathrm{~min}$ at $4^{\circ} \mathrm{C}$. The protein concentration of the supernatant was measured using the bicinchoninic acid Protein Quantification kit (BestBio, Shanghai, China). Supernatant fractions of equal protein concentration $(50 \mu \mathrm{g})$ were subjected to $10 \%$ sodium dodecyl sulfate-polyacrylamide gel electrophoresis and transferred onto polyvinylidene membranes (EMD Millipore, Bedford, MA, USA). Blocking was performed in Tris-buffered saline with $5 \%(\mathrm{w} / \mathrm{v})$ non-fat dry milk for $2 \mathrm{~h}$ at room temperature. Following blocking, the membranes were probed with primary antibodies at $4^{\circ} \mathrm{C}$ overnight. The antibodies used were anti-p-P107 (1:500), anti-P107 (1:250), anti-myostatin (1:500) and anti- $\beta$-actin $(1: 5,000)$. The membranes were washed (6x5 min) with Tris-buffered saline containing Tween-20, and incubated with the appropriate secondary antibody $(1: 5,000)$ for $2 \mathrm{~h}$ at room temperature. The membranes were washed as before and horseradish peroxidase activity was detected using Chemiluminescence reagent (Beyotime Institute of Biotechnology) and exposure to G:BOX Chemi $\mathrm{xT}^{4}$ Gel imaging system instrument (Syngene UK, Cambridge, UK). The blots were quantified by densitometric analysis using the ImageJ software (version 1.46; imagej.nih.gov/ij/).

Statistical analysis. The data are presented as the mean \pm standard error of the mean for at least three individual experiments. All analyses were performed using SPSS 19.0 software (IBM SPSS, Chicago, IL, USA). The results were analyzed by analysis 
Table I. Primer sequences used for reverse transcription-quantitative polymerase chain reaction.

\begin{tabular}{llc}
\hline Gene & \multicolumn{1}{c}{ Primer sequence (5'-3') } & Accession no. \\
\hline $\begin{array}{l}\text { Sirtuin1 } \\
\text { Forward } \\
\text { Reverse } \\
\text { MyoD }\end{array}$ & CCTTGGAGACTGCGATGTTA & NM_019812.2 \\
Forward & ATGAAGAGGTGTTGGTGGC & M84918.1 \\
Reverse & GCCGCCTGAGCAAAGTGAATG \\
$\beta$-Actin & CAGCGGTCCAGGTGCGTAGAAG & EF095208.1 \\
Forward & & \\
Reverse & TGGTGGGAATGGGTCAGAAG & NM_010834 \\
Myostatin & GTAGAAGGTGTGGTGCCAGA & \\
Forward & & \\
Reverse & GATTATCACGCTACGACGGA &
\end{tabular}

of variance, least significant differences test for comparisons between two groups, and correlation analysis. $\mathrm{P}<0.05$ was considered to indicate a statistically significant difference.

\section{Results}

Sirtl regulates the proliferation of C2C12 myoblast cells. To elucidate the role of Sirt1 in the control of $\mathrm{C} 2 \mathrm{C} 12$ myoblast cell growth, $\mathrm{C} 2 \mathrm{C} 12$ cells were treated with resveratrol and NAM (Fig. 1). The present study administered different concentrations of resveratrol on $\mathrm{C} 2 \mathrm{C} 12$ myoblast cells and measured the cells growth after $24 \mathrm{~h}$. The results showed that following treatment of $\mathrm{C} 2 \mathrm{C} 12$ cells with the resveratrol at different concentrations of $10,20,50,100$ or $200 \mu \mathrm{M}$, the cell proliferation index was significantly higher compared with that of the untreated control group $(\mathrm{P}<0.05$; Fig. 1A). Additionally, the results demonstrated that the cell proliferation index of $\mathrm{C} 2 \mathrm{C} 12$ myoblast cells increased with the growth following treatment with resveratrol in a dose-dependent manner when the resveratrol concentration ranged between 0 and $100 \mu \mathrm{M}$ (Pearson correlation coefficient, 0.993). However, when the concentration of resveratrol reached $>100 \mu \mathrm{M}$, the cell proliferation index decreased and the proliferation of cells was inhibited. C2C12 myoblast cell proliferation stabilized at increased doses of resveratrol to $165 \pm 7.2 \%$ (Fig. 1A) of the control group at $100 \mu \mathrm{M}$ and the BrdU positive rate significantly increased by $18.75 \%$ (Fig. 1E).

Subsequently, the effect of different concentrations of NAM on cell growth of C2C12 myoblast cells was detected. It was revealed that following treatment of $\mathrm{C} 2 \mathrm{C} 12$ myoblast cells with NAM at different concentrations of $10,20,40,50$ and $60 \mathrm{mM}$, the cell proliferation index was significantly lower compared with that of the untreated control group $(\mathrm{P}<0.05$; Fig. 1B). In addition, the results revealed that the survival rate of $\mathrm{C} 2 \mathrm{C} 12$ myoblast cells decreased with the increase of NAM concentration in a dose-dependent manner in the NAM concentration range of 0-60 mM. C2C12 myoblast cell viability reached $34 \pm 8.8 \%$ of the untreated cells (Fig. 1B) at $50 \mathrm{mM}$ and the BrdU positive rate was $18.75 \%$ (Fig. 1E). However, when the concentration of NAM reached $>20 \mathrm{mM}$, the cell proliferation rate was rather lower and the cell condition steadily deteriorated (Fig. 1B).

SB431542 promotes the proliferation of C2C12 myoblast cells. It has been demonstrated that SB431542 stimulates proliferation and differentiation, and inhibits the activity of TGF- $\beta 1$ and activin receptor-like kinases (ALKs). It is a selective and potent inhibitor of the phylogenetically related subset of ALK-4 (activin type I receptor) and ALK-5 (TGF $\beta$ type I receptor). The results showed that following treatment with SB431542 at different concentrations of 2, 4, 5 and $10 \mu \mathrm{M}$, the cell proliferation index was significantly higher compared with that of the control group $(\mathrm{P}<0.05$; Fig. 2A). The total number of cells $(255 \pm 10.27$; Fig. 1D) and the BrdU positive rate of $47.73 \pm 1.26 \%$ were both significant compared with the control group (Fig. 1E).

SB431542 relieves the inhibition of C2C12 myoblast cell proliferation by NAM. In order to investigate the role of the myostatin signaling pathway in Sirt1-mediated regulation of C2C12 myoblast cell proliferation, the present study divided C2C12 myoblast cells into four groups and treated with SB431542 $(10 \mu \mathrm{M})$, resveratrol $(100 \mu \mathrm{M}), \mathrm{NAM}(50 \mathrm{mM})$ and a combination of SB431542 $(10 \mu \mathrm{M})$ and NAM $(50 \mathrm{mM})$. The cell growth of $\mathrm{C} 2 \mathrm{C} 12$ myoblast cells was then assessed after $24 \mathrm{~h}$ treatment. Consistent with previous studies, the present results showed that following treatment with SB431542, the cell proliferation index (Fig. 2A) and BrdU positive rate (Fig. 1E) were significantly higher compared with that of the control group $(\mathrm{P}<0.05)$. Following treatment with SB431542 and NAM, the BrdU positive rate and cell viability were significantly higher compared with that of NAM alone $(\mathrm{P}<0.05$; Figs. $1 \mathrm{E}$ and $2 \mathrm{~B}$, respectively). This indicated that Srit1 inhibited the expression of myostatin. By contrast, the inhibition of Sirt1 with NAM may promote the expression of myostatin, therefore, the inhibition of myostatin by SB431542 may release the effect of Sirt1 inhibition.

Myostatin signaling pathway is involved in Sirtl-mediated regulation of $\mathrm{C} 2 \mathrm{C} 12$ myoblast cell proliferation. To confirm 
A

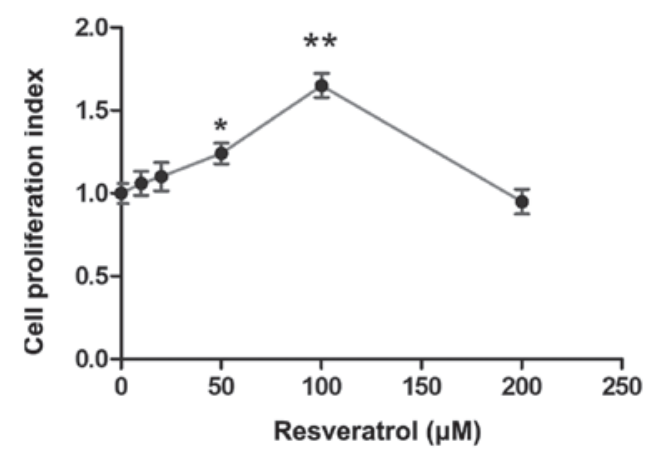

B

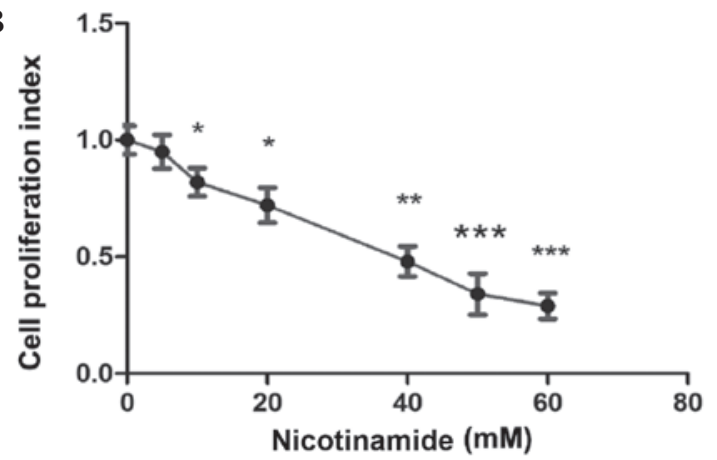

C
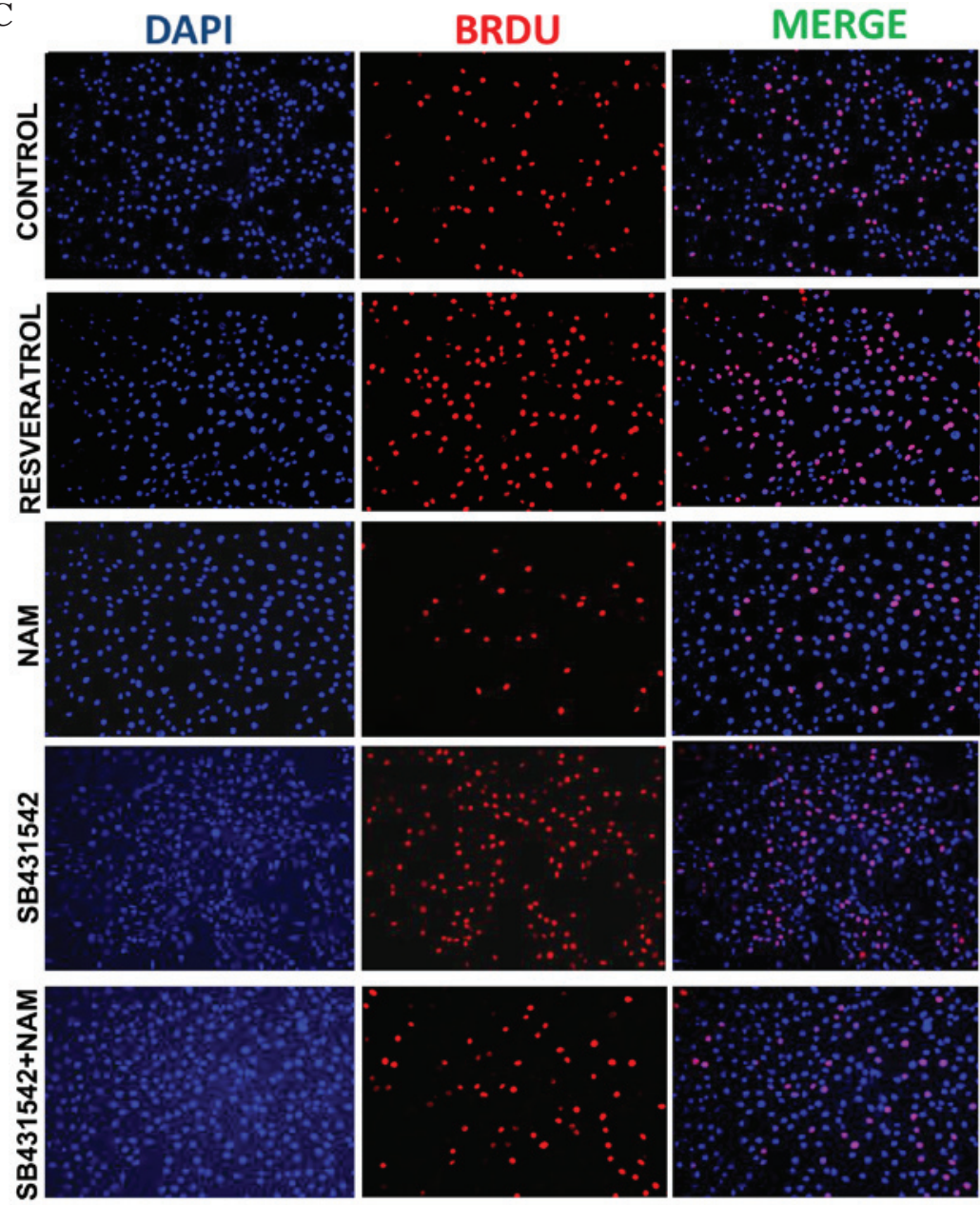

D

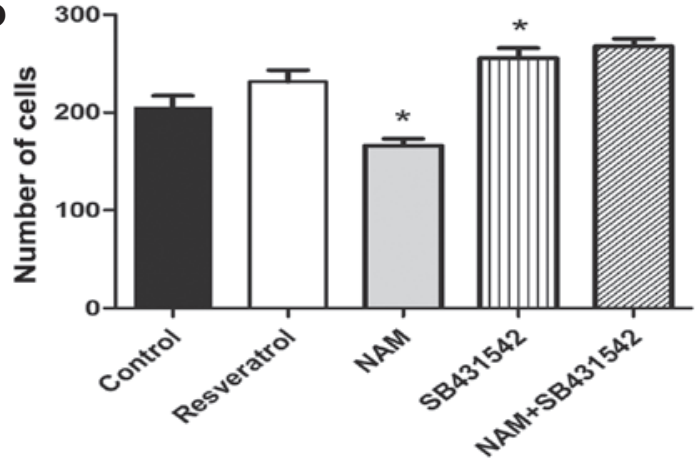

$\mathbf{E}$

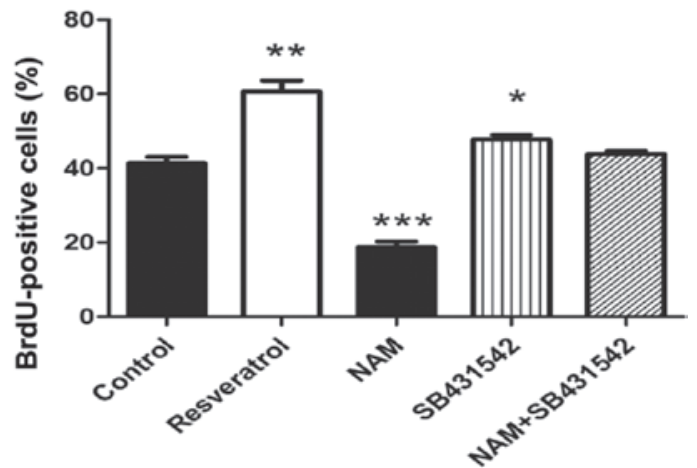

Figure 1. Effects of resveratrol and NAM on the proliferation of C2C12 myoblast cells. C2C12 myoblast cells (8x10 3 cells/100 $\mu 1)$ were seeded into 96 -well plates in triplicate, incubated for 20-24 h and 30 min later were treated with different concentrations of (A) resveratrol and (B) NAM for $24 \mathrm{~h}$. A cell counting kit-8 assay was then performed to analyze proliferation of $\mathrm{C} 2 \mathrm{C} 12$. (C) A BrdU assay was used to detect the proliferation level of $\mathrm{C} 2 \mathrm{C} 12$ cells treated with resveratrol $(100 \mu \mathrm{M})$, NAM $(50 \mathrm{mM})$, SB431542 $(10 \mu \mathrm{M})$ or NAM $(50 \mathrm{mM})+\mathrm{SB} 431542(10 \mu \mathrm{M})$. (D) The total number of BrdU cells were counted and the (E) percentage of BrdU-positive $\mathrm{C} 2 \mathrm{C} 12$ myoblasts was determined. All data are presented as the mean \pm standard error of the mean $\left(\mathrm{n}=3\right.$; ${ }^{*} \mathrm{P}<0.05,{ }^{* * *} \mathrm{P}<0.01$ and ${ }^{* * *} \mathrm{P}<0.001$ vs. control). NAM, nicotinamide; BrdU, bromodeoxyuridine. 

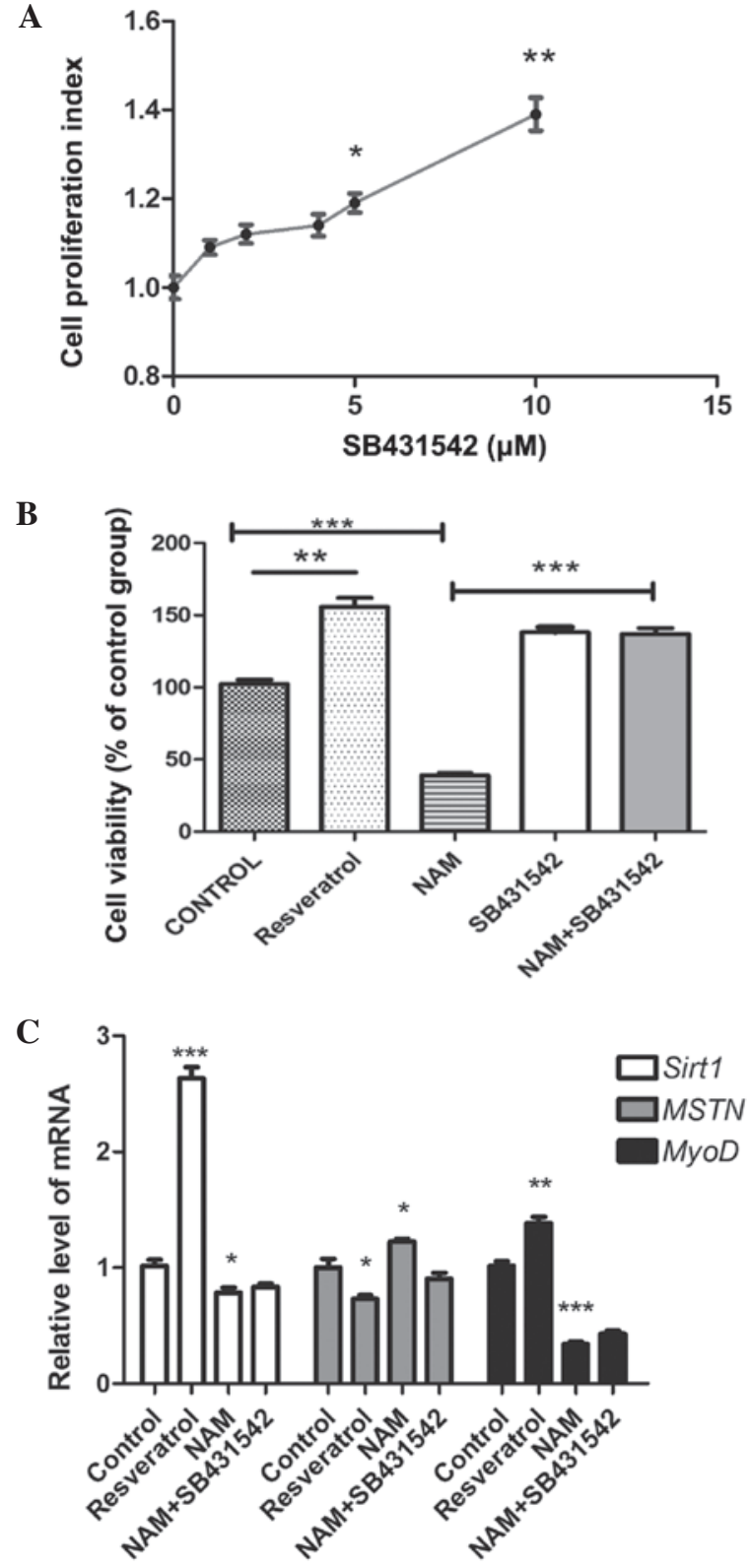

Figure 2. (A) C2C12 myoblast cells were treated with different concentrations of SB431542 for $24 \mathrm{~h}$ and subjected to a cell counting kit- 8 assay to analyze proliferation of $\mathrm{C} 2 \mathrm{C} 12$ myoblast cells. (B) The cell viability of control, resveratrol $(100 \mu \mathrm{M}), \mathrm{NAM}(50 \mathrm{mM}), \mathrm{SB} 431542(10 \mu \mathrm{M})$ and combined group was determined. (C) The mRNA expression levels of Sirt1, MyoD and MSTN were determined by reverse transcription-quantitative polymerase chain reaction. $\beta$-Actin was used as the reference gene. Values are presented as the mean \pm standard error. $\left(\mathrm{n}=3 ;{ }^{*} \mathrm{P}<0.05,{ }^{* *} \mathrm{P}<0.01\right.$ and ${ }^{* * *} \mathrm{P}<0.001$ vs. control). Sirt, Sirtuin; MSTN, myostatin; NAM, nicotinamide.

the role of Sirt1 in $\mathrm{C} 2 \mathrm{C} 12$ cell proliferation, the present study measured the mRNA expression of Sirt1. As shown in Fig. 2C, the mRNA expression of Sirt1 was upregulated by resveratrol treatment $(\mathrm{P}<0.05)$, and was significantly downregulated by NAM treatment $(\mathrm{P}<0.05)$. Notably, the mRNA expression of Sirt1 was significantly higher in cells treated with SB431542 and NAM compared with in cells treated with NAM alone $(\mathrm{P}<0.05)$; however, no significant difference was observed in the mRNA expression of Sirtl between control cells and cells treated with SB431542 and NAM $(\mathrm{P}<0.05)$. These data demonstrated that resveratrol, NAM and
SB431542 combined with NAM induced cell proliferation by the activation or inhibition of Sirtl expression.

MyoD is a myogenic regulatory factor critical for myogenic specification. Previous studies $(19,20)$ reported that myostatin downregulates the expression of MyoD, which indicates that MyoD is the downstream target of myostatin. The members of the retinoblastoma $(R B)$ family include $R B 1 / \mathrm{P} 105, R B 2 / \mathrm{P} 130$ and $R B L 1 / \mathrm{P} 107$ (21-23), and these genes encode retinoblastoma protein $(\mathrm{pRb})$. P107 belongs to a subline of $\mathrm{pRb}$ and has numerous common functions with pRb (24). Additionally, certain research has shown that myostatin may also be involved in the inhibition of myoblast by the $R B 1$ gene, which can be regarded as an indicator of Sirt1 improving C2C12 proliferation via myostatin. Myostatin can inhibit the proliferation of myoblast cells by controlling the transition of G1 to S via the phosphorylation and inactivation of $\mathrm{pRb}(17)$. To determine whether Sirt1 mediated the regulation of $\mathrm{C} 2 \mathrm{C} 12$ myoblast cell proliferation via the myostatin signaling pathway, the present study measured the mRNA expression levels of MyoD and myostatin following treatment with resveratrol, NAM or the combination of SB431542 and NAM. Treatment with resveratrol significantly upregulated the mRNA expression of MyoD $(\mathrm{P}<0.05)$, while the treatment of NAM significantly downregulated the expression of $\mathrm{MyoD}(\mathrm{P}<0.05)$, and the expression of MyoD of C2C12 cells treated with SB431542 and NAM was higher compared with those treated with NAM alone $(\mathrm{P}<0.05)$ (Fig. 2C). However, the mRNA expression of MyoD in the $\mathrm{C} 2 \mathrm{C} 12$ cells treated with SB431542 and NAM showed no notable change compared with the NAM group. Treatment with resveratrol significantly downregulated the mRNA and protein expression levels of myostatin $(\mathrm{P}<0.05$; Figs. $2 \mathrm{C}, 3 \mathrm{~A}$ and $\mathrm{B})$. Treatment with NAM significantly downregulated the protein expression of p-P107 ( $\mathrm{P}<0.05$; Fig. 3A and $\mathrm{C})$, and significantly upregulated the protein expression levels of myostatin and P107 (Fig. 3B and D). The expression of p-P107 was significantly higher in cells treated with SB431542 and NAM compared with those treated with NAM alone. By contrast, the expression of P107 was significantly lower in cells treated with SB431542 and NAM compared with those treated with NAM alone $(\mathrm{P}<0.05)$.

\section{Discussion}

Sirtl serves a critical role in cell proliferation; however, the mechanism remains to be fully understood. Kabra et al (25) found that Sirt1 inhibits cell proliferation in colon cancer, while Pardo et al (26) conversely reported that Sirt1 promoted the proliferation and suppressed the differentiation of myoblast precursors. Rathbone et al (11) found that Sirtl overexpression promoted the proliferation of skeletal muscle precursor cells, which may be due to the different cell type. In the present study, the Sirtl activator resveratrol promoted the proliferation of C2C12 myoblast cells (Fig. 1A and E), while its inhibitor NAM decreased the proliferation of $\mathrm{C} 2 \mathrm{C} 12$ myoblast cells (Fig. 1B and E).

The present data showed that Sirt1 promotes the proliferation of $\mathrm{C} 2 \mathrm{C} 12$ myoblast cells only when resveratrol concentration was $\leq 100 \mu \mathrm{M}$. When resveratrol concentration was $>100 \mu \mathrm{M}$, the survival rate of $\mathrm{C} 2 \mathrm{C} 12$ myoblast cells decreased. This may be due to the toxic effect of the solvent DMSO on the cells. By contrast, resveratrol can not only activate Sirt1, but also 


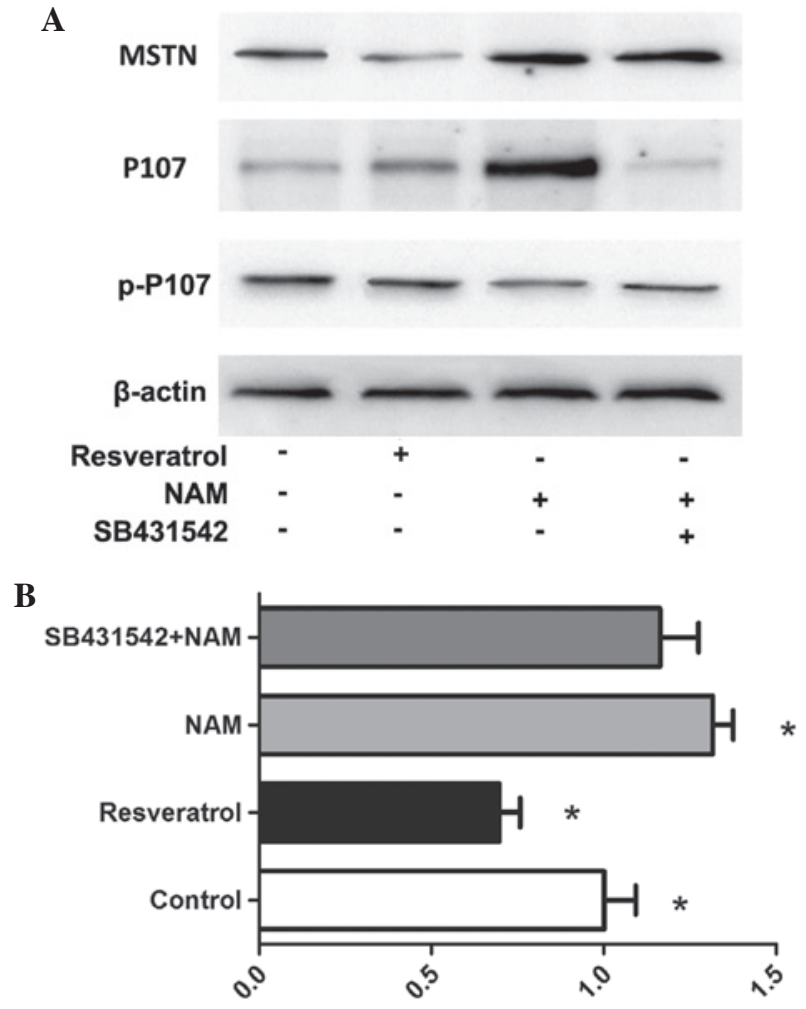

Relative expression of MSTN
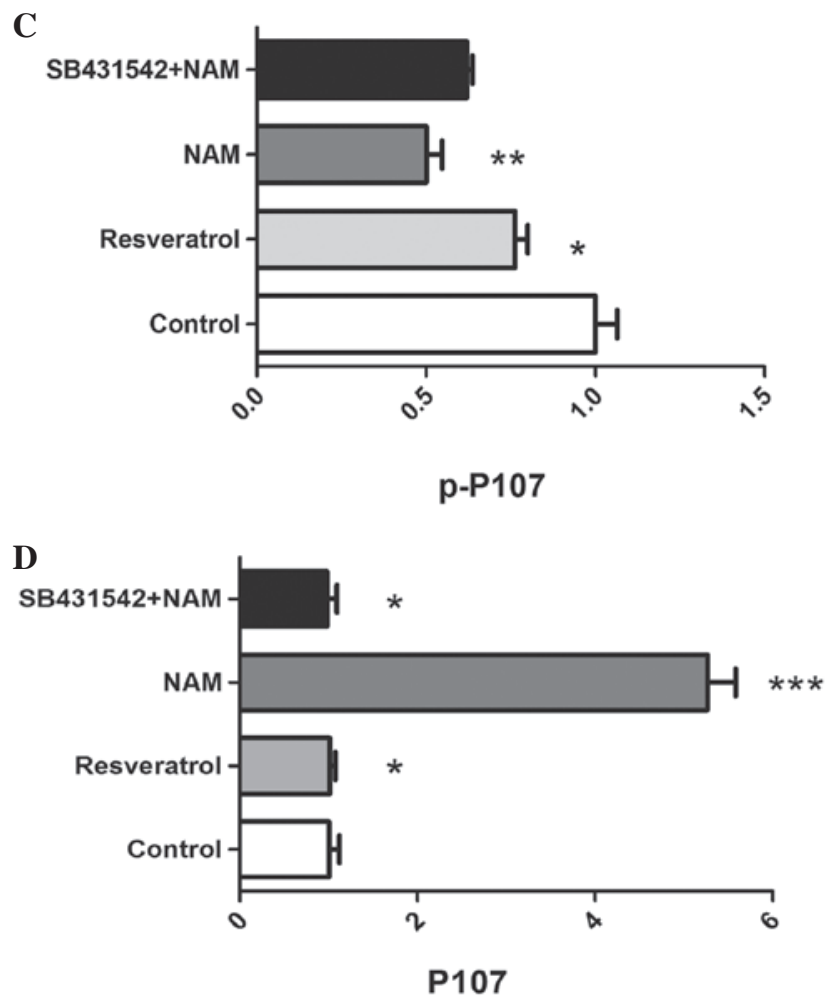

Figure 3. (A) Western blotting was performed to determine the relative protein expression levels of MSTN, P107 and p-P107. Quantitative analysis of the (B) MSTN, (C) P107 and (D) p-P107 levels. The data are presented as the mean \pm standard error of the mean $\left(\mathrm{n}=3 ;{ }^{*} \mathrm{P}<0.05,{ }^{* *} \mathrm{P}<0.01\right.$ and ${ }^{* * * *} \mathrm{P}<0.001$ vs. control). MSTN, myostatin; p-, phosphorylated

inhibits lipoxygenase (27), cyclooxygenase (28) and various protein kinases, therefore, as a result resveratrol may be toxic to cells when its concentration is too high.
Myostatin, a member of the TGF- $\beta$ signaling pathway, is a negative regulator of skeletal muscle mass (16). Myostatin acts on muscle tissue by binding a cell-bound receptor called activin type II receptor, for example ALK4 and 5, which effect the phosphorylation of receptor Smad proteins 2/3 (29). SB431542 is a small molecule inhibitor of ALK4 and 5, and it can inhibit the myostatin signaling pathway. Certain previous studies found that myostatin inhibits the proliferation of $\mathrm{C} 2 \mathrm{C} 12$ myoblast cells $(30,31)$. Another previous study found that SB431542 also promotes the enlargement of $\mathrm{C} 2 \mathrm{C} 12$ myotube diameter, and thus promotes the differentiation of $\mathrm{C} 2 \mathrm{C} 12$ myoblast cells. Consistent with the previous studies, the present study found that SB431542 promotes the proliferation of $\mathrm{C} 2 \mathrm{C} 12$ myoblast cells in a concentration-dependent manner (Fig. 2A). Myostatin can inhibit G1 phase of the myoblast cell cycle and subsequently interfere with the progression into $\mathrm{S}$ phase to inhibit myoblast proliferation by increasing p21 expression and hypophosphorylated $\mathrm{pRb}$ (17). It has also been reported that when cells are close to the end of $\mathrm{G} 1$ phase, $\mathrm{pRb}$ is phosphorylated by cyclin-dependent kinase (CDK) and acetylated, and Sirt1 can inhibit $\mathrm{Rb}$ activity by deacetylation (32). The intersection between myostatin and Sirt1 on cell phase regulation suggested that certain interaction between myostatin and Sirt1 signaling exists. Indeed, the present results indicated that the myostatin signaling pathway is involved in the regulation of cell proliferation by Sirt1. The present data showed that inhibition of the myostatin signaling pathway can effectively alleviate the inhibition effect of NAM on the proliferation of C2C12 myoblast cells (Figs. 1E and 2B). To confirm the interaction between myostatin and Sirt1, the mRNA expression of Sirt1 was determined following treatment with resveratrol, NAM or a combination of NAM and SB431542. As shown in Fig. 2C, resveratrol and NAM decreased and increased Sirtl expression in $\mathrm{C} 2 \mathrm{C} 12$ myoblast cells, respectively. Our previous results indicated that the survival rate was higher in cells treated with SB431542 and NAM compared with in cells treated with NAM alone. Consistent with this, the mRNA expression of Sirt1 was significantly higher in cells treated with SB431542 and NAM compared with those treated with NAM alone. This demonstrated that myostatin can inversely affect Sirt1 expression.

To further confirm this, the expression levels of myostatin and its downstream proteins were assessed. Certain previous studies found that myostatin overexpression can reduce MyoD protein levels during cell proliferation and differentiation (19,33). P107 is involved in the cell cycle and belongs to a subline of $\mathrm{pRb}$, which are downstream molecules of myostatin. Western blot analysis was used to assess the protein expression levels of myostatin and P107. It was demonstrated that myostain expression was reduced following treatment with resveratrol for $24 \mathrm{~h}$ (Fig. 3A). However, for C2C12 myoblast cells treated with NAM, the protien expression levels of myostatin and P107 were significantly upregulated, while the protein expression of p-P107 was downregulated (Fig 3A-D). Notably, treatment with NAM significantly reduced the mRNA expression levels of MyoD. When the C2C12 myoblast cells were co-incubated with SB431542 and NAM, the mRNA expression of MyoD and the protein expression of p-P107 were higher, and P107 expression was significantly lower compared 
with those cells incubated with NAM alone. This suggested that inhibition of the myostatin pathway attenuated the inhibitory effect of NAM by P107 protein phosphorylation. Previous studies have demonstrated that myostatin may regulate the proliferation of cells via $\mathrm{p} 21$, which has been demonstrated to be an inhibitor of cyclin D-CDK4/6 activity. Additionally Thomas et al (17) found that myostatin can upregulate the expression of $\mathrm{p} 21^{\mathrm{Waf} 1 / \mathrm{Cip} 1}$ and decrease the expression and activity of CDK2 protein, which may be due to the accumulation of hypo-phosphorylated $\mathrm{pRb}$, thus leading to the arrest of myoblasts in G1 phase of the cell cycle, subsequently inhibiting cell proliferation (17). Additionally, the overexpression of Sirt1 caused adverse effects, for example, Sirt1 overexpression induced a decrease of $\mathrm{p} 21^{\mathrm{Waf} 1 / \mathrm{Cip} 1}$ expression (34). Since the present study found that Sirt1 activation downregulated the myostatin signaling pathway, it was speculated that Sirt1 promoted cell proliferation by inhibiting the myostatin signaling pathway.

Taken together, these data indicated that myostatin is involved in the regulation of $\mathrm{C} 2 \mathrm{C} 12$ myoblast cell proliferation via Srit1 and that myostatin can affect Srit1 expression. Further studies are warranted to elucidate the underlying mechanisms of how Sirtl affects myostatin signaling.

\section{Acknowledgements}

The present study was supported by the National Natural Science Foundation of China (no. 81271943).

\section{References}

1. Cheng HL, Mostoslavsky R, Saito S, Manis JP, Gu Y, Patel P, Bronson R, Appella E, Alt FW and Chua KF: Developmental defects and p53 hyperacetylation in Sir2 homolog (SIRT1)-deficient mice. Proc Natl Acad Sci USA 100: 10794-1099, 2003.

2. McBurney MW, Yang X, Jardine K, Hixon M, Boekelheide K, Webb JR, Lansdorp PM and Lemieux M: The mammalian SIR2alpha protein has a role in embryogenesis and gametogenesis. Mol Cell Biol 23: 38-54, 2003.

3. Horio Y, Hayashi T, Kuno A and Kunimoto R: Cellular and molecular effects of sirtuins in health and disease. Clin Sci (Lond) 121: 191-203, 2011.

4. Ferrara N, Rinaldi B, Corbi G, Conti V, Stiuso P, Boccuti S, Rengo G, Rossi F and Filippelli A: Exercise training promotes SIRT1 activity in aged rats. Rejuvenation Res 11: 139-150, 2008

5. Howitz KT, Bitterman KJ, Cohen HY, Lamming DW, Lavu S, Wood JG, Zipkin RE, Chung P, Kisielewski A, Zhang LL, et al: Small molecule activators of sirtuins extend Saccharomyces cerevisiae lifespan. Nature 425: 191-196, 2003.

6. Jackson MD, Schmidt MT, Oppenheimer NJ and Denu JM: Mechanism of nicotinamide inhibition and transglycosidation by Sir2 histone/protein deacetylases. J Biol Chem 278: 50985-50998, 2003.

7. Sauve AA, Moir RD, Schramm VL and Willis IM: Chemical activation of Sir2-dependent silencing by relief of nicotinamide inhibition. Mol Cell 17: 595-601, 2005.

8. Ohanna M, Bonet C, Bille K, Allegra M, Davidson I, Bahadoran P, Lacour JP, Ballotti R and Bertolotto C: SIRT1 promotes proliferation and inhibits the senescence-like phenotype in human melanoma cells. Oncotarget 5: 2085-2095, 2014.

9. Mao B, Hu F, Cheng J, Wang P, Xu M, Yuan F, Meng S, Wang Y, Yuan $\mathrm{Z}$ and $\mathrm{Bi}$ W: SIRT1 regulates YAP2-mediated cell proliferation and chemoresistance in hepatocellular carcinoma. Oncogene 33: 1468-1474, 2014.

10. Hori YS, Kuno A, Hosoda R, Tanno M, Miura T, Shimamoto K and Horio Y: Resveratrol ameliorates muscular pathology in the dystrophic mdx mouse, a model for duchenne muscular dystrophy. J Pharmacol Exp Ther 338: 784-794, 2011
11. Rathbone CR, Booth FW and Lees SJ: Sirt1 increases skeletal muscle precursor cell proliferation. Eur J Cell Biol 88: 35-44, 2009.

12. Tanno M, Sakamoto J, Miura T, Shimamoto K and Horio Y: Nucleocytoplasmic shuttling of the NAD+-dependent histone deacetylase SIRT1. J Biol Chem 282: 6823-6832, 2007.

13. Ripoli M, Barbano R, Balsamo T, Piccoli C, Brunetti V, Coco M, Mazzoccoli G, Vinciguerra M and Pazienza V: Hypermethylated levels of E-cadherin promoter in Huh-7 cells expressing the HCV core protein. Virus Res 160: 74-81, 2011.

14. Haigis MC and Sinclair DA: Mammalian sirtuins: Biological insights and disease relevance. Annu Rev Pathol 5: 253-295, 2010.

15. Ota H, Tokunaga E, Chang K, Hikasa M, Iijima K, Eto M, Kozaki K, Akishita M, Ouchi Y and Kaneki M: Sirt1 inhibitor, Sirtinol, induces senescence-like growth arrest with attenuated Ras-MAPK signaling in human cancer cells. Oncogene 25: 176-185, 2006.

16. McPherron AC, Lawler AM and Lee SJ: Regulation of skeletal muscle mass in mice by a new TGF-beta superfamily member. Nature 387: 83-90, 1997.

17. Thomas M, Langley B, Berry C, Sharma M, Kirk S, Bass J and Kambadur R: Myostatin, a negative regulator of muscle growth, functions by inhibiting myoblast proliferation. J Biol Chem 275: 40235-40243, 2000

18. Zhang C, Mcfarlane C, Lokireddy S, Bonala S, Ge X, Masuda S, Gluckman PD, Sharma M and Kambadur R: Myostatin-deficient mice exhibit reduced insulin resistance through activating the AMP-activated protein kinase signalling pathway. Diabetologia 54: 1491-1501, 2011.

19. Langley B, Thomas M, Bishop A, Sharma M, Gilmour S and Kambadur R: Myostatin inhibits myoblast differentiation by down-regulating MyoD expression. J Biol Chem 277: 49831-49840, 2002.

20. Spiller MP, Kambadur R, Jeanplong F, Thomas M, Martyn JK, Bass JJ and Sharma M: The myostatin gene is a downstream target gene of basic helix-loop-helix transcription factor MyoD. Mol Cell Biol 22: 7066-7082, 2002.

21. Ewen ME, Xing YG, Lawrence JB and Livingston DM: Molecular cloning, chromosomal mapping and expression of the cDNA for $\mathrm{p} 107$, a retinoblastoma gene product-related protein. Cell 66: 1155-1164, 1991.

22. Hannon GJ, Demetrick D and Beach D: Isolation of the Rb-related p130 through its interaction with CDK2 and cyclins. Genes Dev 7: 2378-2391, 1993.

23. Mayol X, Graña X, Baldi A, Sang N, Hu Q and Giordano A: Cloning of a new member of the retinoblastoma gene family (pRb2) which binds to the E1A transforming domain. Oncogene 8: 2561-2566, 1993.

24. Assoian RK and Yung Y: A reciprocal relationship between $\mathrm{Rb}$ and Skp2: Implications for restriction point control, signal transduction to the cell cycle and cancer. Cell Cycle 7: 24-27, 2008.

25. Kabra N, Li Z, Chen L, Li B, Zhang X, Wang C, Yeatman T, Coppola D and Chen J: SirT1 is an inhibitor of proliferation and tumor formation in colon cancer. J Biol Chem 284: 18210-18217, 2009.

26. Pardo PS and Boriek AM: The physiological roles of Sirt1 in skeletal muscle. Aging (Albany NY) 3: 430-437, 2011.

27. Olas B and Wachowicz B: Resveratrol, a phenolic antioxidant with effects on blood platelet functions. Platelets 16: 251-260, 2005.

28. Banerjee S, Bueso-Ramos C and Aggarwal BB: Suppression of 7,12-dimethylbenz (a)anthracene-induced mammary carcinogenesis in rats by resveratrol: Role of nuclear factor-kappaB, cyclooxygenase 2 , and matrix metalloprotease 9 . Cancer Res 62: 4945-4954, 2002.

29. Lee SJ: Regulation of muscle mass by myostatin. Annu Rev Cell Dev Biol 20: 61-86, 2004

30. Taylor WE, Bhasin S, Artaza J, Byhower F, Azam M, Willard DH Jr, Kull FC Jr and Gonzalez-Cadavid N: Myostatin inhibits cell proliferation and protein synthesis in $\mathrm{C} 2 \mathrm{C} 12$ muscle cells. Am J Physiol Endocrinol Metab 280: E221-E228, 2001.

31. Rios R, Carneiro I, Arce VM and Devesa J: Myostatin regulates cell survival during C2C12 myogenesis. Biochem Biophys Res Commun 280: 561-566, 2001

32. Wong S and Weber JD: Deacetylation of the retinoblastoma tumour suppressor protein by SIRT1. Biochem J 407: 451-460, 2007.

33. Joulia D, Bernardi H, Garandel V, Rabenoelina F, Vernus B and Cabello G: Mechanisms involved in the inhibition of myoblast proliferation and differentiation by myostatin. Exp Cell Res 286: 263-275, 2003.

34. Rathbone CR, Lees SJ and Booth F: Sirt1 increases satellite cell cycle progression. FASEB 21, 2007. 